\title{
Correction to: Impairment of testicular development in rats exposed to acephate during maternal gestation and lactation
}

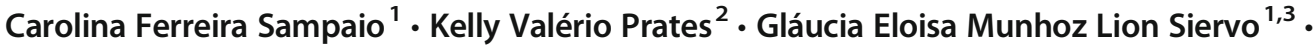 \\ Paulo Cezar de Freitas Mathias ${ }^{2}$ - Glaura Scantamburlo Alves Fernandes ${ }^{1}$ (D)
}

Published online: 20 January 2020

(C) Springer-Verlag GmbH Germany, part of Springer Nature 2020

Correction to: Environmental Science and Pollution Research https://doi.org/10.1007/s11356-019-07209-0

The original publication of this paper contains a mistake.

The correct name for the 4th Author is shown in this paper.

The original article was corrected.

The online version of the original article can be found at https://doi.org/ 10.1007/s11356-019-07209-0

$\triangle$ Glaura Scantamburlo Alves Fernandes glaura@uel.br

1 Department of General Biology, Biological Sciences Center, State University of Londrina-UEL, Rodovia Celso Garcia Cid, Pr $445 \mathrm{Km}$ 380, Londrina, Paraná 86057-970, Brazil

2 Department of Biotechnology, Genetics and Cell Biology, State University of Maringá - UEM, 5790, Maringá, Paraná 87020-900, Brazil

3 Department of General Pathology, Biological Sciences Center, State University of Londrina-UEL, Londrina, Paraná 86057-970, Brazil 